\title{
Preference for Oral and Injectable GLP-1 RA Therapy Profiles in Japanese Patients with Type 2 Diabetes: A Discrete Choice Experiment
}

\author{
Ataru Igarashi · Brian Bekker Hansen · Jakob Langer · Francesca Tavella • \\ Hannah Collings · Neil Davies · Robin Wyn
}

Received: August 14, 2020 / Accepted: November 4, 2020 / Published online: November 27, 2020

(C) The Author(s) 2020

\begin{abstract}
Introduction: Glucagon-like peptide 1 (GLP-1) receptor agonists (RAs) approved to date are administered by injection; therefore, patient perceptions of an oral GLP-1 RA are unknown. This discrete choice experiment explored preferences for (unbranded) oral and injectable GLP-1 RA profiles among Japanese patients with type 2 diabetes (T2D).

Methods: An online survey was designed using literature review and qualitative interview findings, and administered to Japanese patients with T2D

Electronic Supplementary Material The online version of this article (https://doi.org/10.1007/s12325020-01561-1) contains supplementary material, which is available to authorized users.
\end{abstract}

A. Igarashi

Unit of Public Health and Preventive Medicine, Yokohama City University School of Medicine, Kanagawa, Japan

A. Igarashi

Department of Health Economics and Outcomes Research, Graduate School of Pharmaceutical

Sciences, The University of Tokyo, Tokyo, Japan

B. Bekker Hansen

Novo Nordisk A/S, Søborg, Denmark

J. Langer $(\varangle)$

Novo Nordisk Pharma Ltd., Tokyo, Japan

e-mail: jklg@novonordisk.com

F. Tavella $\cdot$ H. Collings $\cdot$ N. Davies $\cdot$ R. Wyn Adelphi Values PROVE, Cheshire, UK and $\mathrm{HbA}_{1 \mathrm{c}} \geq 7.0 \%$ receiving oral antiglycaemic medication (with no experience of injectable antiglycaemic medication). Therapy profiles were created using Japanese head-to-head trial data for orally administered semaglutide (7 mg and $14 \mathrm{mg})$, injectable dulaglutide $(0.75 \mathrm{mg})$, and injectable liraglutide $(0.9 \mathrm{mg})$. Profiles were not labelled. Choice tasks tested preference between hypothetical profiles, preference between profiles with actual trial data, and willingness to initiate treatment. Relative importance of attributes was determined using conditional logit regression.

Results: A total of 500 respondents were analysed: mean age 61.2 years; $93.8 \%$ male; mean $\mathrm{HbA}_{1 \mathrm{c}} 7.6 \%$; 78.2\% with $\mathrm{HbA}_{1 \mathrm{c}} \geq 7.0$ to $<8 \%$; $89 \%$ with $\mathrm{HbA}_{1 \mathrm{c}}$ above personal target. Mean BMI was $25.4 \mathrm{~kg} / \mathrm{m}^{2} ; 49 \%$ had obesity ( $\geq 25 \mathrm{~kg} /$ $\mathrm{m}^{2}$ ). The treatment attribute with greatest importance was mode and frequency of administration (49.1\%), followed by nausea risk (30.8\%), weight change $(11.3 \%)$, and $\mathrm{HbA}_{1 \mathrm{c}}$ change $(8.8 \%)$. Oral semaglutide 7 and $14 \mathrm{mg}-$ like profiles were both preferred: the $7 \mathrm{mg}$-like profile was preferred over dulaglutide (by 91.0\% of respondents) and liraglutide (by 89.4\%); the $14 \mathrm{mg}$-like profile was preferred over dulaglutide (by $88.2 \%$ ) and liraglutide (by 94.4\%). Willingness to initiate treatment was also higher for orally administered semaglutide-like profiles: $62.4 \%$ with $7 \mathrm{mg}$ and $64.0 \%$ with $14 \mathrm{mg}$, versus $13.6 \%$ and $11.0 \%$ with injectable GLP-1 RA-like profiles. Subgroup results were generally consistent with the overall sample. 
Conclusion: Japanese patients with T2D appear to prefer oral GLP-1 RA profiles over injectable GLP-1 RA profiles, and administration appears to be the most important factor in this decision. This highlights the unmet need for an effective and orally administered GLP-1 RA for the treatment of T2D in Japan.

Keywords: Discrete choice experiment; GLP-1 receptor agonist; Patient preference; Type 2 diabetes (T2D)

\section{Key Summary Points}

Why carry out this study?

Type 2 diabetes mellitus (T2DM) may be treated with GLP-1 receptor agonist (RA) therapies.

All GLP-1 RA therapies marketed to date are administered by injection; therefore, it is unknown how an oral formulation of a GLP-1 RA would be perceived by patients.

This discrete choice experiment explored preferences for (unbranded) oral and injectable therapy profiles (based on GLP1 RAs) among Japanese patients with type 2 diabetes mellitus.

\section{What was learned from the study?}

Orally administered semaglutide-like profiles were preferred by $89.4-91.0 \%$ and 88.2-94.4\% of respondents when compared to injectable dulaglutide- or liraglutide-like profiles, and respondents were more often willing to initiate treatment with an orally administered semaglutide-like profile $(62.4-64.0 \%$ versus $13.6 \%$ and $11.0 \%)$; mode and frequency of administration was shown to have the highest relative importance among attributes.

Japanese patients with T2DM appear to prefer oral GLP-1 RA profiles over injectable GLP-1 RA profiles, highlighting the possible value of a new GLP-1 RA therapy with this characteristic to patients.
In comparisons of these oral and injectable GLP-1 RAs, the treatment attribute with highest relative importance was mode and frequency of administration, followed by risk of nausea.

\section{DIGITAL FEATURES}

This article is published with digital features, including a summary slide, to facilitate understanding of the article. To view digital features for this article go to https://doi.org/10.6084/ m9.figshare.13187582.

\section{INTRODUCTION}

Type 2 diabetes (T2D) is a chronic metabolic condition characterised by deficient secretion of insulin along with insulin resistance, and subsequent poor glycaemic control [1]. As a result of the chronic nature and high prevalence of T2D, this condition is associated with a high burden on healthcare systems [2]. This burden may become more severe in countries such as Japan, where population aging is likely to lead to an increase in the country-wide prevalence of diabetes towards $10 \%$ over the next decades $[3,4]$.

In Japan, patients with T2D are typically treated with dipeptidyl peptidase 4 inhibitors, either as monotherapy or in combination with other oral drug classes such as biguanides or sulfonylureas $[5,6]$. However, approximately half of Japanese patients on one or multiple oral antidiabetic drugs (OADs) do not achieve the standard glycated haemoglobin $\left(\mathrm{HbA}_{1 \mathrm{c}}\right)$ target of $<7.0 \%$ [7-9].

Many injectable therapies of the glucagonlike peptide 1 (GLP-1) receptor agonist (RA) class (including semaglutide, dulaglutide, exenatide, liraglutide, and lixisenatide) have also been developed and approved for use in Japan [10-17]. In addition, a new oral formulation of semaglutide has been investigated in Japanese patients with T2D $[18,19]$. However, it is unknown how Japanese patients with T2D 
perceive differences in the characteristics and outcomes of oral and injectable GLP-1 RA therapies.

The discrete choice experiment (DCE, or "conjoint analysis") is an established methodology in patient preference research $[20,21]$. Such studies have previously been used to assess patient preferences among injectable GLP-1 RA therapies, both in Japan $[22,23]$ and in other regions [24-28]. However, to date, patient preferences for oral GLP-1 RA therapies have not been explored using this method, in any region.

In order to expand on the existing knowledge in this area, the current study aimed to determine the relative preference of Japanese patients with T2D for oral and injectable GLP-1 RA therapies. To accomplish this, a DCE was conducted, incorporating unbranded profiles of three GLP-1 RA therapies (one oral; two injectable) at clinically relevant doses, based on head-to-head trial data in Japanese patients with T2D.

\section{METHODS}

\section{Development of Survey}

A DCE survey was designed to fulfil the pre-defined research aim, in line with findings from a targeted literature review, findings from qualitative interviews with patients and physicians, and information from sources such as clinical trial results and product labels. Additionally, statistical methods were used to determine the optimal final design of the survey.

The targeted literature review (conducted in August 2018) identified precedents for DCE study design, examples of best practice for such studies, and the most commonly reported treatment attributes in published T2D DCE studies. Treatment attributes that had commonly been tested in previous studies were taken forward to create an initial list of proposed attributes to be presented in the current DCE survey.

The final treatment attributes for presentation in the DCE survey were then determined through qualitative research in Japan: interviews with experienced healthcare professionals $(n=10)$, and focus groups including patients with T2D ( $n=80$ across four groups). Participants commented on whether proposed attributes and levels were relevant and understandable, and were able to suggest additional relevant attributes and presentation methods, if these were missing; these interviews confirmed the validity of proposed attributes, and identified suitable methods of presenting each one.

Before qualitative interviews with patients were conducted, ethics approval for involving Japanese patients with T2D in research was granted by Clinical Research Promotion Network Japan (http://www.sct-net.org/; approval number 201812-02). This approval additionally covered involvement of Japanese patients with T2D in the later DCE survey.

In order to generate realistic attribute levels, product characteristics and head-to-head clinical trial data were used for a new oral GLP-1 RA (orally administered semaglutide) currently under review by the Japanese Pharmaceuticals and Medical Devices Agency and the two most widely used GLP-1 RAs in Japan (injectable dulaglutide and injectable liraglutide).

Clinical outcomes data were obtained from Japanese clinical trials: PIONEER 9 (which tested $3 \mathrm{mg}, 7 \mathrm{mg}$, or $14 \mathrm{mg}$ orally administered semaglutide versus $0.9 \mathrm{mg}$ liraglutide, both as monotherapy), and PIONEER 10 (which tested $3 \mathrm{mg}, 7 \mathrm{mg}$, and $14 \mathrm{mg}$ orally administered semaglutide versus $0.75 \mathrm{mg}$ dulaglutide, both in combination with one OAD) $[18,19]$.

Minimum and maximum data for relevant treatment doses from PIONEER 9 and PIONEER 10 were used to define realistic ranges for efficacy and safety attribute levels, and additional hypothetical values were added within these ranges. Specifically, data for the $7 \mathrm{mg}$ and $14 \mathrm{mg}$ doses of orally administered semaglutide were used, as $7 \mathrm{mg}$ is expected to be the maintenance dose in Japan, with possible dose escalation to $14 \mathrm{mg}$ for patients who may require this. Comparably, dulaglutide $0.75 \mathrm{mg}$ and liraglutide $0.9 \mathrm{mg}$ are current maintenance doses in Japan, with no higher doses approved for use at the time the current study was conducted. 


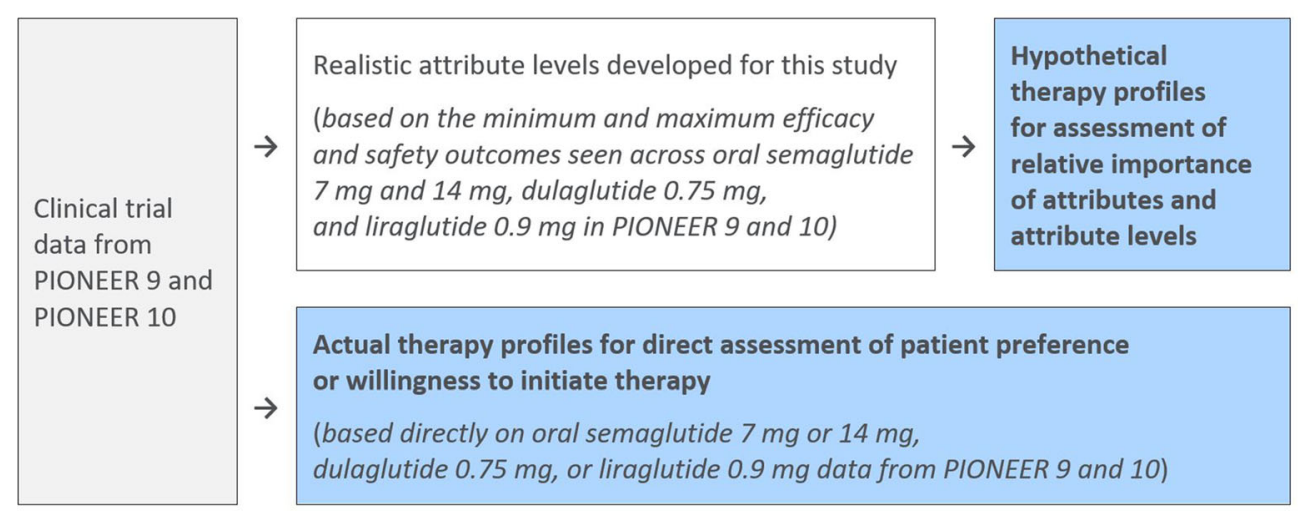

Fig. 1 Summary of how Japanese trial data was used to create therapy profiles

Two forms of therapy profiles were generated to test patient preference (Fig. 1): "hypothetical" profiles were assembled from the list of realistic attribute levels developed for this study; "actual" profiles were designed to directly replicate the efficacy and safety of a given GLP-1 RA therapy as seen in the PIONEER 9 and 10 trials, or averaged between the two trials (in the case of the oral semaglutide treatment profiles). Specifically, choice sets comparing orally administered semaglutide and liraglutide used PIONEER 9 data only, and choice sets comparing orally administered semaglutide and dulaglutide used PIONEER 10 data only. However, when orally administered semaglutide $7 \mathrm{mg}$ or $14 \mathrm{mg}$ profiles were presented alone, averaged results from PIONEER 9 and PIONEER 10 were used, to provide a realistic estimate of the efficacy and safety of these two doses across a larger patient population of broader background.

Hypothetical therapy profiles (and choice sets including these profiles) were generated using a fractional factorial design in the "support.CEs" package within $R$, which also distributed the generated choice sets into six appropriately sized blocks for use in the survey [29].

\section{Final Survey}

Each tested profile included the four attributes validated within qualitative research: mode, frequency, and requirements of administration; change in glycated haemoglobin $\left(\mathrm{HbA}_{1 \mathrm{c}}\right)$ level as a result of treatment, over 6 months; change in weight as a result of treatment, over 6 months; risk of nausea when initiating treatment.

Three approaches were taken to test respondents' preferences: choice sets of hypothetical profiles, choice sets of actual profiles for direct preference comparisons, and actual profiles presented alone to test willingness to initiate treatment.

Table 1 presents the list of attribute levels used to generate hypothetical profiles, as informed by the minimum and maximum efficacy and safety values seen in actual profiles.

Although all included therapy profiles were based on characteristics and clinical data of available GLP-1 RA therapies, this fact was not revealed to respondents, who were instead only asked to consider "new treatments". When profiles were presented in choice sets (each containing two profiles), respondents were required to select one (and only one) profile from each choice set, and did not have an option to skip choice sets.

The overall structure and block design of the survey are presented in the supplementary material.

Data on the relative importance of attributes and attribute levels were first collected using choice sets including two hypothetical GLP-1 RA-like profiles each.

Each individual respondent was assigned to one of six blocks, each of which contained eight unique hypothetical choice sets and one fixed hypothetical choice set which was kept 
Table 1 Final attribute levels developed for presentation in hypothetical GLP-1 RA-like profiles

Level as presented to respondents Rationale

Mode and frequency of administration

Tablet taken once per day, at least $30 \mathrm{~min}$ before the first meal or Oral administration of semaglutide drink of the day and taking other oral medications

Injection taken once per week, from a single-use pre-filled injection Administration of dulaglutide pen

Injection taken once per day, from a multiple-use pre-filled

Administration of liraglutide injection pen

Change in $\mathrm{HbA}_{1 \mathrm{c}}$

On average, patients achieve a $2.0 \%$-point reduction in $\mathrm{HbA}_{1 \mathrm{c}}$ level over 6 months of treatment

On average, patients achieve a $1.8 \%$-point reduction in $\mathrm{HbA}_{1 \mathrm{c}}$ level over 6 months of treatment

On average, patients achieve a $1.6 \%$-point reduction in $\mathrm{HbA}_{1 \mathrm{c}}$ level over 6 months of treatment

On average, patients achieve a 1.4\%-point reduction in $\mathrm{HbA}_{1 \mathrm{c}}$ level over 6 months of treatment

Highest $\mathrm{HbA}_{1 \mathrm{c}}$ reduction seen at 26 weeks in PIONEER 9 or PIONEER 10 trial data ${ }^{a}$

Hypothetical value

Hypothetical value

Lowest $\mathrm{HbA}_{1 \mathrm{c}}$ reduction seen at 26 weeks in PIONEER 9 or PIONEER 10 trial data ${ }^{a}$

Change in weight

On average, patients experience a weight loss of $2.4 \mathrm{~kg}$ over 6 months of treatment

On average, patients experience a weight loss of $1.5 \mathrm{~kg}$ over 6 months of treatment

On average, patients experience a weight loss of $0.6 \mathrm{~kg}$ over 6 months of treatment

On average, patients experience a weight gain of $0.3 \mathrm{~kg}$ over 6 months of treatment

"Most favourable" weight change seen at 26 weeks in PIONEER 9 or PIONEER 10 trial data ${ }^{a}$

Hypothetical value

Hypothetical value

"Least favourable" weight change seen at 26 weeks in PIONEER 9 or PIONEER 10 trial data ${ }^{a}$

Risk of nausea

When beginning to take this medicine, 9 out of 100 patients feel transient nausea (without vomiting)

Highest nausea rate reported in PIONEER 9 or PIONEER 10 trial data

When beginning to take this medicine, 6 out of 100 patients feel Hypothetical value transient nausea (without vomiting)

When beginning to take this medicine, 4 out of 100 patients feel Hypothetical value transient nausea (without vomiting) 
Table 1 continued

\begin{tabular}{|c|c|}
\hline Level as presented to respondents & Rationale \\
\hline $\begin{array}{l}\text { When beginning to take this medicine, } 2 \text { out of } 100 \text { patients feel } \\
\text { transient nausea (without vomiting) }\end{array}$ & $\begin{array}{l}\text { Lowest nausea rate reported in PIONEER } 9 \text { or } \\
\text { PIONEER } 10 \text { trial data }\end{array}$ \\
\hline
\end{tabular}

identical across blocks (to serve as a test of consistency between respondents). Therefore, a total of 49 of these sets were presented to collect preference data.

Two further hypothetical choice sets were presented to all respondents, but were not used to measure preference results. Before all other hypothetical choice sets, respondents completed an example choice set, where one profile was clearly inferior. Any respondent who selected the clearly inferior profile was prompted to reconsider their decision, and was not allowed to progress without selecting the alternative (clearly superior) profile. After completing all other hypothetical choice sets, respondents completed a test choice set, where one profile was again clearly inferior. In this case, any respondent who selected the clearly inferior profile was excluded from the final analysis, as it was assumed that they misunderstood the scenario or outcomes data being presented in each choice set, and therefore provided invalid answers.

Data on respondents' direct preference for actual therapy profiles were collected using four choice sets based on head-to-head clinical trial data from PIONEER 9 and 10. Two choice sets compared profiles based on orally administered semaglutide $7 \mathrm{mg}$ or $14 \mathrm{mg}$ with a profile based on dulaglutide $0.75 \mathrm{mg}$ (PIONEER 10), and two choice sets compared profiles based on orally administered semaglutide $7 \mathrm{mg}$ or $14 \mathrm{mg}$ with a profile based on liraglutide $0.9 \mathrm{mg}$ (PIONEER 9). Each respondent completed all four choice sets.
Data on respondents' willingness to initiate treatment with actual therapy profiles were then collected using four separately presented profiles based on GLP-1 RAs: orally administered semaglutide $7 \mathrm{mg}$, orally administered semaglutide $14 \mathrm{mg}$, dulaglutide $0.75 \mathrm{mg}$, and liraglutide $0.9 \mathrm{mg}$. For each profile, respondents were required to describe their willingness to initiate treatment, by selecting one of the following options, with no option to skip: "very unwilling", "unwilling", "neutral", "willing", "very willing".

Further questions collected demographic and disease-specific data, and assessed if respondents had adequate health literacy and numeracy (to validate findings, rather than to inform inclusion or exclusion from the final analysis sample) [22, 30, 31]. Adequate health literacy was defined as achieving a total of at least 12 on three questions regarding self-assessed health literacy, each of which was scored from 1 to 5 . Adequate numeracy was defined as answering at least three of five numeracy test questions correctly.

\section{Survey Respondents}

Potential respondents from a large pre-existing panel of individuals living with T2D were contacted via email to participate in the survey. As respondents could decline to participate, or be excluded during their participation in the survey, respondents were continually recruited until 500 evaluable sets of results were captured. 
Eligible respondents were adults (age at least 20 years) who were permanently resident in Japan, who were able to understand and respond to survey questions presented in Japanese, with no employment in the pharmaceutical industry or employment in treatment of diabetes, and who fulfilled the following diabetes-related criteria: diagnosis of T2D (and no other type of diabetes); receiving oral medications to control blood glucose level (at the time of the survey, and for at least 6 months prior); never receiving injectable medications to control blood glucose level; $\mathrm{HbA}_{1 \mathrm{c}}$ level of $\geq 7.0 \%$ at the latest time of measuring (within the past year).

All eligible respondents also confirmed their willingness to participate, and gave explicit informed consent to participate in the survey, and for their demographic data and preference data to be captured and stored for research purposes, and reported in an anonymized manner. All respondents received $¥ 750$ as compensation for their participation in the survey.

\section{Data Analysis}

A test of validity was applied before responses were analysed. Any respondents who selected treatment $\mathrm{A}$ in all choice sets or selected treatment $B$ in all choice sets were excluded from the final analysis sample, as it was assumed that these respondents selected profiles on the basis of their physical position within choice sets, rather than by considering attribute levels.

The analyses of hypothetical choice set results used a conditional logit regression model to regress stated preferences, in order to determine the crude relative preference for each attribute. Only main effects were estimated, i.e. no interaction terms were examined.

The coefficients on the independent variables from the regression were interpreted as relative preference weights, indicating the relative strength of preference for each attribute level. A larger positive coefficient indicated that respondents preferred that attribute level to levels that had smaller or negative coefficients. The difference in preference weight between the most preferred level of an attribute and the least preferred level of the same attribute also provided an estimate of that attribute's overall importance.

For pre-specified subgroup analyses, respondents were grouped by age ( $<60$ or $\geq 60$ years), by $\mathrm{HbA}_{1 \mathrm{c}}$ level in relation to objective or subjective targets $\left(\mathrm{HbA}_{1 \mathrm{c}}<8 \%\right.$ or $\geq 8 \% ; \mathrm{HbA}_{1 \mathrm{c}}$ within or above personal target), by presence of obesity (BMI $<25 \mathrm{~kg} / \mathrm{m}^{2}$ or $\geq 25 \mathrm{~kg} / \mathrm{m}^{2}$ ), and by health-related quality of life (HRQoL) (impairment or no impairment by EQ-5D-5L). In later post hoc analysis, results were also analysed by respondent gender (male or female), given the skewed gender distribution in the final sample. Respondents' utility by EQ-5D-5L was calculated by applying the established Japanese EQ5D-5L value set.

\section{RESULTS}

\section{Characteristics of Survey Respondents}

Of the total of 4018 respondents who initiated the survey, $3518(87.6 \%)$ did not complete the survey. The majority of these excluded respondents did not meet the pre-defined inclusion/ exclusion criteria set out in the patient screener; other reasons for exclusion included refusing to participate, or providing invalid answers within the survey (Table 2). Therefore, the final analysis sample included 500 respondents.

Demographic characteristics for the final analysis sample of 500 respondents are reported in Table 3.

The majority of respondents were male $(93.8 \%)$. The mean age of respondents was 61.2 years $( \pm 9.3)$, and the majority of respondents (67.2\%) were aged between 50 and 69. All respondents had completed junior high school, and most respondents had attained at least a degree-level education (62.2\%). The majority of respondents were currently in full time employment $(56.8 \%)$, or were retired $(25.4 \%)$, at the time of the survey. Most respondents $(72.6 \%)$ reported a household income between $¥ 2,000,000$ and $¥ 10,000,000$ (in USD, approximately $\$ 18,600$ and $\$ 93,200$ ). 
Table 2 Attrition of survey respondents

\begin{tabular}{|c|c|c|}
\hline \multirow{2}{*}{$\begin{array}{l}\text { Original (and subsequent) } \\
\text { number of respondents }\end{array}$} & \multicolumn{2}{|r|}{ Number of respondents excluded at each stage, with reasons } \\
\hline & $\rightarrow$ & $2(0.1 \%)$ were aged $0-19$ years \\
\hline \multicolumn{3}{|l|}{$\downarrow$} \\
\hline 4016 & $\rightarrow$ & $1(0.0 \%)$ was not a permanent resident of Japan \\
\hline \multicolumn{3}{|l|}{$\downarrow$} \\
\hline 4015 & $\rightarrow$ & $0(0.0 \%)$ were not able to read and understand the Japanese language \\
\hline \multicolumn{3}{|l|}{$\downarrow$} \\
\hline 4015 & $\rightarrow$ & 206 (5.1\%) had been diagnosed with type 1 diabetes or gestational diabetes \\
\hline \multicolumn{3}{|l|}{$\downarrow$} \\
\hline $\begin{array}{l}3809 \\
\downarrow\end{array}$ & $\rightarrow$ & $\begin{array}{l}1103(29.0 \%) \text { did not take oral medications to control blood glucose level, or } \\
\text { took a combination of oral and injectable medications }\end{array}$ \\
\hline 2706 & $\rightarrow$ & $20(0.7 \%)$ had been taking oral medications for only $0-5$ months \\
\hline \multicolumn{3}{|l|}{$\downarrow$} \\
\hline \multicolumn{3}{|r|}{ 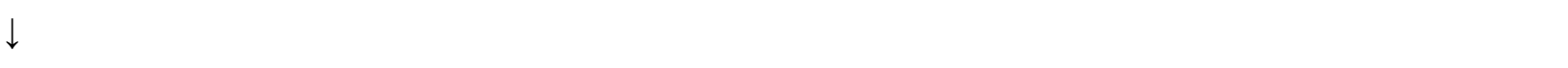 } \\
\hline $\begin{array}{l}2262 \\
\downarrow\end{array}$ & $\rightarrow$ & $\begin{array}{l}1409(62.3 \%) \text { had a most recent measured } \mathrm{HbA}_{1 \mathrm{c}} \text { level below } 7.0 \% \text {, or did not } \\
\text { know a measured } \mathrm{HbA}_{1 \mathrm{c}} \text { level from within the past year }\end{array}$ \\
\hline \multicolumn{3}{|r|}{ 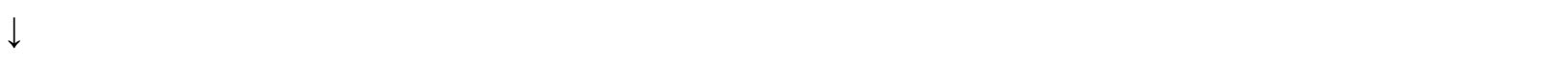 } \\
\hline 819 & $\rightarrow$ & $\begin{array}{l}11(1.3 \%) \text { worked for a pharmaceutical company, or were employed in } \\
\text { a position where they directly treated patients with diabetes }\end{array}$ \\
\hline \multicolumn{3}{|r|}{ 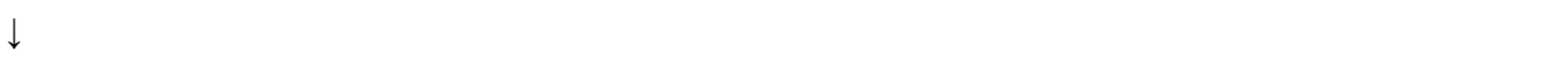 } \\
\hline \multicolumn{3}{|r|}{ 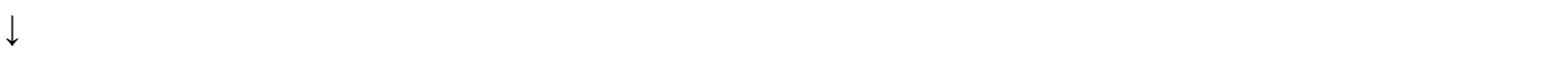 } \\
\hline $\begin{array}{l}521 \\
\downarrow\end{array}$ & $\rightarrow$ & $\begin{array}{l}21(4.0 \%) \text { selected treatment } A \text { in all choice sets, or treatment } B \text { in all choice } \\
\text { sets }\end{array}$ \\
\hline $\begin{array}{l}500 \text { respondents (final analysi } \\
\text { sample) }\end{array}$ & & \\
\hline
\end{tabular}

$H b A_{1 c}$ glycated haemoglobin 
Table 3 Demographic characteristics of final analysis sample

\begin{tabular}{|c|c|}
\hline \multicolumn{2}{|l|}{ Gender } \\
\hline Female & $31(6.2 \%)$ \\
\hline Male & $469(93.8 \%)$ \\
\hline \multicolumn{2}{|l|}{ Age, years } \\
\hline Mean $( \pm S D)$ & $\begin{array}{l}61.2 \\
\quad( \pm 9.3)\end{array}$ \\
\hline Minimum & 35 \\
\hline Maximum & 81 \\
\hline \multicolumn{2}{|l|}{ Age category, years } \\
\hline $20-29$ & $0(0.0 \%)$ \\
\hline $30-39$ & $5(1.0 \%)$ \\
\hline $40-49$ & $54(10.8 \%)$ \\
\hline $50-59$ & $159(31.8 \%)$ \\
\hline $60-69$ & $177(35.4 \%)$ \\
\hline$\geq 70$ & $105(21.0 \%)$ \\
\hline \multicolumn{2}{|l|}{ Education level attained } \\
\hline Elementary school & $0(0.0 \%)$ \\
\hline Junior high school & $8(1.6 \%)$ \\
\hline Senior high school & $125(25.0 \%)$ \\
\hline $\begin{array}{l}\text { Vocational qualification/community } \\
\text { college }\end{array}$ & $56(11.2 \%)$ \\
\hline Undergraduate degree & $288(57.6 \%)$ \\
\hline Postgraduate degree & $20(4.0 \%)$ \\
\hline Doctorate & $3(0.6 \%)$ \\
\hline \multicolumn{2}{|l|}{ Employment status } \\
\hline Full-time employment & $284(56.8 \%)$ \\
\hline Part-time employment & $41(8.2 \%)$ \\
\hline Volunteer & $4(0.8 \%)$ \\
\hline Student & $0(0.0 \%)$ \\
\hline Unemployed & $44(8.8 \%)$ \\
\hline Retired & $127(25.4 \%)$ \\
\hline \multicolumn{2}{|l|}{ Household income, million yen } \\
\hline$<1$ & $6(1.2 \%)$ \\
\hline
\end{tabular}

Table 3 continued

\begin{tabular}{ll}
\hline$\geq 1,<2$ & $20(4.0 \%)$ \\
$\geq 2,<4$ & $112(22.4 \%)$ \\
$\geq 4,<6$ & $110(22.0 \%)$ \\
$\geq 6,<8$ & $72(14.4 \%)$ \\
$\geq 8,<10$ & $69(13.8 \%)$ \\
$\geq 10,<12$ & $25(5.0 \%)$ \\
$\geq 12,<14$ & $9(1.8 \%)$ \\
$\geq 14,<16$ & $12(2.4 \%)$ \\
$\geq 16$ & $17(3.4 \%)$ \\
\hline
\end{tabular}

Data are presented as $n$ (\%) unless otherwise stated $n$ sample size, $S D$ standard deviation

Clinical characteristics for the final analysis sample of 500 respondents are reported in Table 4.

Respondents' mean reported $\mathrm{HbA}_{1 \mathrm{c}}$ was $7.6 \%$ $( \pm 0.8)$. All respondents had $\mathrm{HbA}_{1 \mathrm{c}} \geq 7 \%$ (as per the survey inclusion criteria), and $78.2 \%$ of respondents had $\mathrm{HbA}_{1 \mathrm{c}}$ in the range $\geq 7 \%$ to $<8 \%$. Most respondents (89.0\%) reported that their current $\mathrm{HbA}_{1 \mathrm{c}}$ was above the personal target they had discussed with their physician.

Respondents' mean BMI was $25.4 \mathrm{~kg} / \mathrm{m}^{2}$ $( \pm 4.0)$ : approximately half of respondents (49.0\%) would have been considered obese $(B M I \geq 25)$, and very few $(1.0 \%)$ would have been considered underweight $(\mathrm{BMI}<18.5)$ [32].

A minority of respondents reported experiencing T2D-related complications (9.0\%), and the most common of these complications was eye problems (5.8\%). No respondents had received injectable treatment for glycaemia in T2D (as per the study inclusion criteria), and only $0.8 \%$ of respondents had received self-administered injectable therapies not related to diabetes in the past.

Respondents' mean utility by EQ-5D-5L was $0.90( \pm 0.06) ; 66.6 \%$ of respondents reported the best possible health state (i.e. a health state of 11111, signifying no problems in the five presented dimensions of HRQoL). These results appear broadly consistent with previously reported data on EQ-5D-5L norms in Japan: 
Table 4 Clinical characteristics of final analysis sample

\begin{tabular}{|c|c|}
\hline Height, cm & $168.4( \pm 6.7)$ \\
\hline Weight, kg & $72.2( \pm 13.4)$ \\
\hline BMI, $\mathrm{kg} / \mathrm{m}^{2}$ & $25.4( \pm 4.0)$ \\
\hline Duration of T2D, years & $12.5( \pm 7.8)$ \\
\hline Recent $\mathrm{HbA}_{1 \mathrm{c}}$ level & $7.6( \pm 0.8)$ \\
\hline \multicolumn{2}{|l|}{ Recent $\mathrm{HbA}_{1 \mathrm{c}}$ level category } \\
\hline$\geq 7.0 \%,<7.5 \%$ & $287(57.4 \%)$ \\
\hline$\geq 7.5 \%,<8.0 \%$ & $104(20.8 \%)$ \\
\hline$\geq 8.0 \%,<8.5 \%$ & $56(11.2 \%)$ \\
\hline$\geq 8.5 \%,<9.0 \%$ & $16(3.2 \%)$ \\
\hline$\geq 9.0 \%$ & $37(7.4 \%)$ \\
\hline \multicolumn{2}{|c|}{$\begin{array}{l}\text { Recent } \mathrm{HbA}_{1 \mathrm{c}} \text { level below or above personal target } \\
\text { discussed with physician }\end{array}$} \\
\hline Below target & $42(8.4 \%)$ \\
\hline Above target & $444(88.8 \%)$ \\
\hline Don't know & $14(2.8 \%)$ \\
\hline \multicolumn{2}{|l|}{ Current oral T2D treatment } \\
\hline One medication only & $137(27.4 \%)$ \\
\hline Two medications only & $175(35.0 \%)$ \\
\hline Three or more medications & $188(37.6 \%)$ \\
\hline \multicolumn{2}{|c|}{ Complications related to diabetes } \\
\hline Any complications & $45(9.0 \%)$ \\
\hline Kidney disease & $0(0.0 \%)$ \\
\hline Tingling or loss of feeling & $9(1.8 \%)$ \\
\hline Eye problems & $29(5.8 \%)$ \\
\hline Heart disease & $12(2.4 \%)$ \\
\hline Other complications & $1(0.2 \%)$ \\
\hline
\end{tabular}

Data are presented as $n(\%)$ or mean $( \pm \mathrm{SD})$

$B M I$ body mass index, $H b A_{1 c}$ glycated haemoglobin, $n$ sample size, $S D$ standard deviation, $T 2 D$ type 2 diabetes

mean utility of $0.94,0.94,0.91$, and 0.87 among men aged 40-49, 50-59, 60-69, and $\geq 70$ years respectively, with $63.5 \%, 63.4 \%, 54.4 \%$, and $41.9 \%$ of men in those age groups reporting the best possible health state [33].
Additionally, the proportion of respondents with at least an adequate level of self-reported health literacy was $100.0 \%$, and the proportion with adequate numeracy was $98.8 \%$.

\section{Relative Importance of Attributes and Levels in Hypothetical Profiles}

Examining the difference in preference weight (i.e. contribution to profile utility) between the most and least preferred levels of an attribute allows estimation of the importance of that attribute to patients, relative to the others [34].

According to analysis of 4500 responses to hypothetical choice sets (nine per respondent included in the final analysis), the attribute that accounted for the largest proportion of the variance in respondents' decision-making was mode and frequency of administration, with a relative change in preference weight between least and most preferred levels of $1.72 ; 49.1 \%$ as a percentage of total. This attribute was followed by risk of nausea $(1.08 ; 30.8 \%)$, change in weight $(0.40 ; 11.3 \%)$, and lastly change in $\mathrm{HbA}_{1 \mathrm{c}}(0.31 ; 8.8 \%)$.

The estimated increase or decrease in relative preference weight when moving from one attribute level to another is presented in Fig. 2.

The three level changes associated with the largest relative increase in preference were "daily injection to daily tablet administration" (+1.72), "9/100 risk of nausea to $2 / 100$ risk of nausea" $(+1.08)$, and "weekly injection to daily tablet administration" (+1.01). All other level changes were associated with a relative preference change of 0.46 or less.

Of note, the relative preference weight of levels increased linearly (and according to the expected trend) in mode and frequency of administration, $\mathrm{HbA}_{1 \mathrm{c}}$ change, and risk of nausea. However, in weight change, relative preference weights did not increase linearly across all levels: the relative preference weight for " $1.5 \mathrm{~kg}$ decrease" was lower than those of "0.6 kg decrease" or " $2.4 \mathrm{~kg}$ decrease", and not significantly different to that of " $0.3 \mathrm{~kg}$ decrease" $(p=0.023)$.

Further detail on estimated preference increases or decreases between attribute levels, 


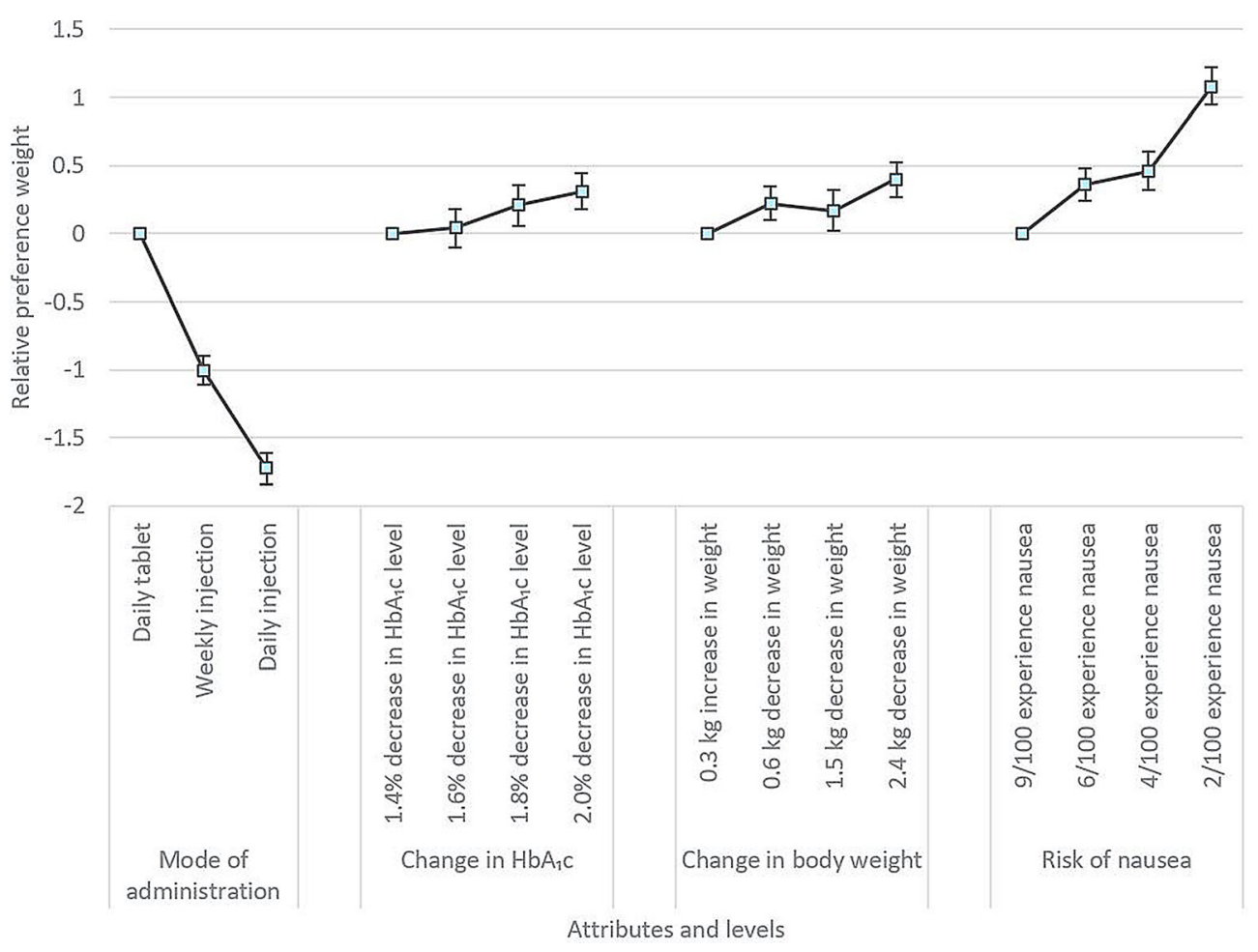

Fig. 2 Relative preference weights for each attribute level presented in hypothetical choice sets

and their statistical significance, are presented in Table 5.

In subgroup analyses (by age, $\mathrm{HbA}_{1 \mathrm{c}}$ levels in relation to guideline target and personal targets, BMI, HRQoL, and gender), variation in ranking of attributes was observed, but mode and administration remained the most important characteristic in all subgroups, while risk of nausea was the second most important characteristic in 11 of 12 subgroups. No subgroup results were significantly different to those of the overall analysis sample (see supplementary material).

\section{Relative Preference for Actual Therapy Profiles}

Analyses of responses for each choice set including (unbranded) actual therapy profiles showed that profiles based on orally administered semaglutide were preferred by $88.2-94.4 \%$ of respondents in all comparisons (Fig. 3). Specifically, the oral semaglutide 7 mg-like profile was preferred over profiles based on dulaglutide $0.75 \mathrm{mg}$ (by $91.0 \%$ of respondents) and liraglutide $0.9 \mathrm{mg}$ (by $89.4 \%$ of respondents); the oral semaglutide $14 \mathrm{mg}$-like profile was preferred over profiles based on dulaglutide $0.75 \mathrm{mg}$ (by $88.2 \%$ of respondents) and liraglutide $0.9 \mathrm{mg}$ (by $94.4 \%$ of respondents).

In subgroup analyses (by age, $\mathrm{HbA}_{1 \mathrm{c}}$ levels in relation to guideline target and personal targets, BMI, HRQoL, and gender), the proportion of respondents preferring profiles based on orally administered semaglutide $7 \mathrm{mg}$ did not vary beyond $85.5 \%$ and $94.7 \%$, and the proportion of respondents preferring profiles based on orally administered semaglutide $14 \mathrm{mg}$ did not vary beyond $82.8 \%$ and $98.0 \%$. In six cases, a direct preference result was significantly different to that from the overall analysis sample; in each case, the profile based on orally administered semaglutide was preferred by a significantly higher proportion of respondents (see supplementary material). 
Table 5 Relative preference weights for each attribute level presented in hypothetical choice sets

\begin{tabular}{|c|c|c|c|}
\hline Attribute level & Coefficient ${ }^{a}$ & Lower and upper CI & $p$ value \\
\hline \multicolumn{4}{|c|}{ Mode and frequency of administration } \\
\hline Daily tablet & (Reference) & & \\
\hline Weekly injection & -1.01 & -1.11 to -0.90 & $<0.001$ \\
\hline Daily injection & -1.72 & -1.84 to -1.61 & $<0.001$ \\
\hline \multicolumn{4}{|l|}{ Change in $\mathrm{HbA}_{1 \mathrm{c}}$} \\
\hline $1.4 \%$ decrease in $\mathrm{HbA}_{1 \mathrm{c}}$ level & (Reference) & & \\
\hline $1.6 \%$ decrease in $\mathrm{HbA}_{1 \mathrm{c}}$ level & 0.04 & -0.10 to 0.18 & 0.559 \\
\hline $1.8 \%$ decrease in $\mathrm{HbA}_{1 \mathrm{c}}$ level & 0.21 & 0.06 to 0.36 & 0.005 \\
\hline $2.0 \%$ decrease in $\mathrm{HbA}_{1 \mathrm{c}}$ level & 0.31 & 0.18 to 0.44 & $<0.001$ \\
\hline \multicolumn{4}{|l|}{ Change in weight } \\
\hline $0.3 \mathrm{~kg}$ increase in weight & (Reference) & & \\
\hline $0.6 \mathrm{~kg}$ decrease in weight & 0.22 & 0.10 to 0.35 & $<0.001$ \\
\hline $1.5 \mathrm{~kg}$ decrease in weight & 0.17 & 0.02 to 0.32 & 0.023 \\
\hline $2.4 \mathrm{~kg}$ decrease in weight & 0.40 & 0.27 to 0.52 & $<0.001$ \\
\hline \multicolumn{4}{|l|}{ Risk of nausea } \\
\hline 9/100 experience nausea & (Reference) & & \\
\hline 6/100 experience nausea & 0.36 & 0.24 to 0.48 & $<0.001$ \\
\hline 4/100 experience nausea & 0.46 & 0.32 to 0.60 & $<0.001$ \\
\hline 2/100 experience nausea & 1.08 & 0.95 to 1.22 & $<0.001$ \\
\hline
\end{tabular}

$C I$ confidence interval, $H b A_{1 c}$ glycated haemoglobin

a Coefficient represents the difference in preference weight between that level and the reference level; positive coefficients represent increased preference for a level versus the reference, while negative coefficients represent decreased preference for a level versus the reference

\section{Willingness to Initiate Treatment with Actual Therapy Profiles}

According to analyses of responses to actual therapy profiles presented alone, respondents were more often willing (i.e. answered "willing" or "very willing") to initiate treatment with orally administered semaglutide-like profiles, compared to profiles based on dulaglutide or liraglutide.

Specifically, $62.4 \%$ and $64.0 \%$ of respondents were willing to initiate treatment with profiles based on orally administered semaglutide
$7 \mathrm{mg}$ and $14 \mathrm{mg}$, respectively; corresponding results were $13.6 \%$ and $11.0 \%$ for profiles based on dulaglutide $0.75 \mathrm{mg}$ and liraglutide $0.9 \mathrm{mg}$, respectively (Fig. 4).

In subgroup analyses (by age, $\mathrm{HbA}_{1 \mathrm{c}}$ levels in relation to guideline target and personal targets, BMI, HRQoL, and gender), one significant difference was seen: respondents with $\mathrm{HbA}_{1 \mathrm{c}} \geq 8 \%$ were significantly more willing to initiate treatment with a profile based on orally administered semaglutide $14 \mathrm{mg}$, relative to the overall analysis sample (see supplementary material). 


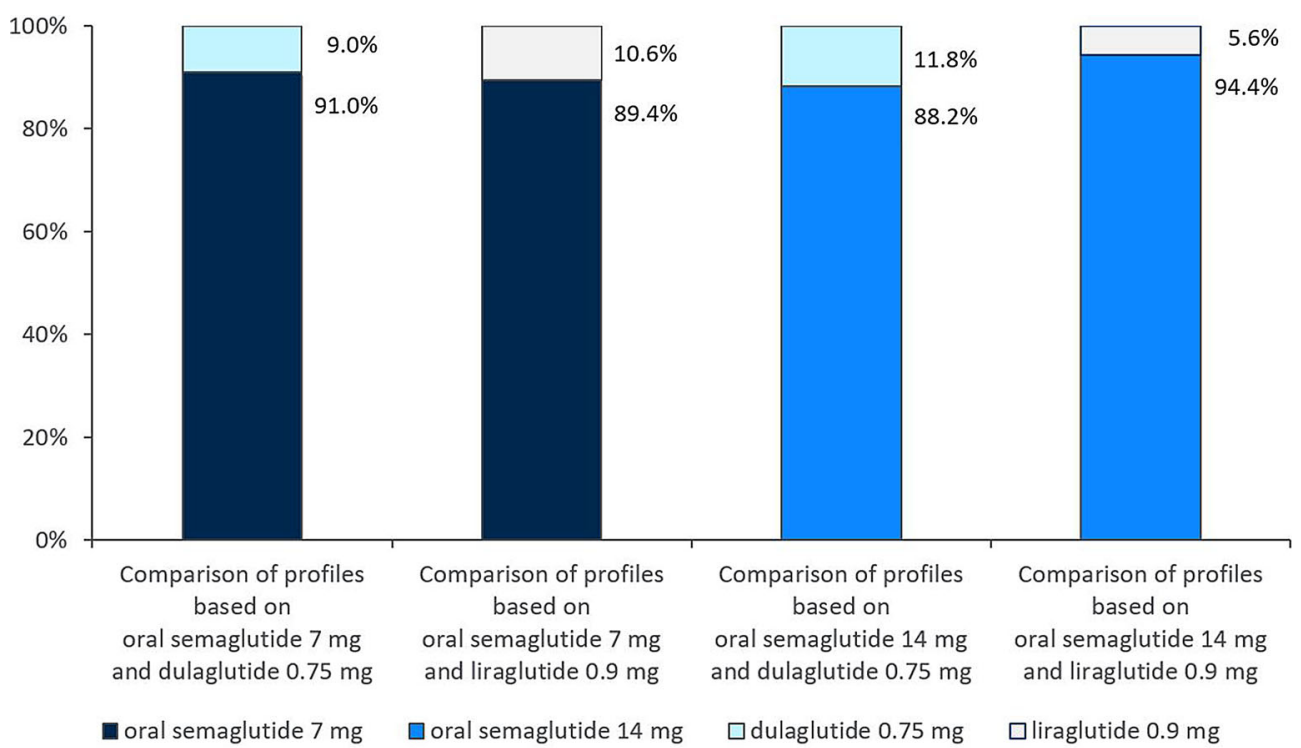

Fig. 3 Respondents' preferred profiles in comparisons of four profiles based on actual therapies

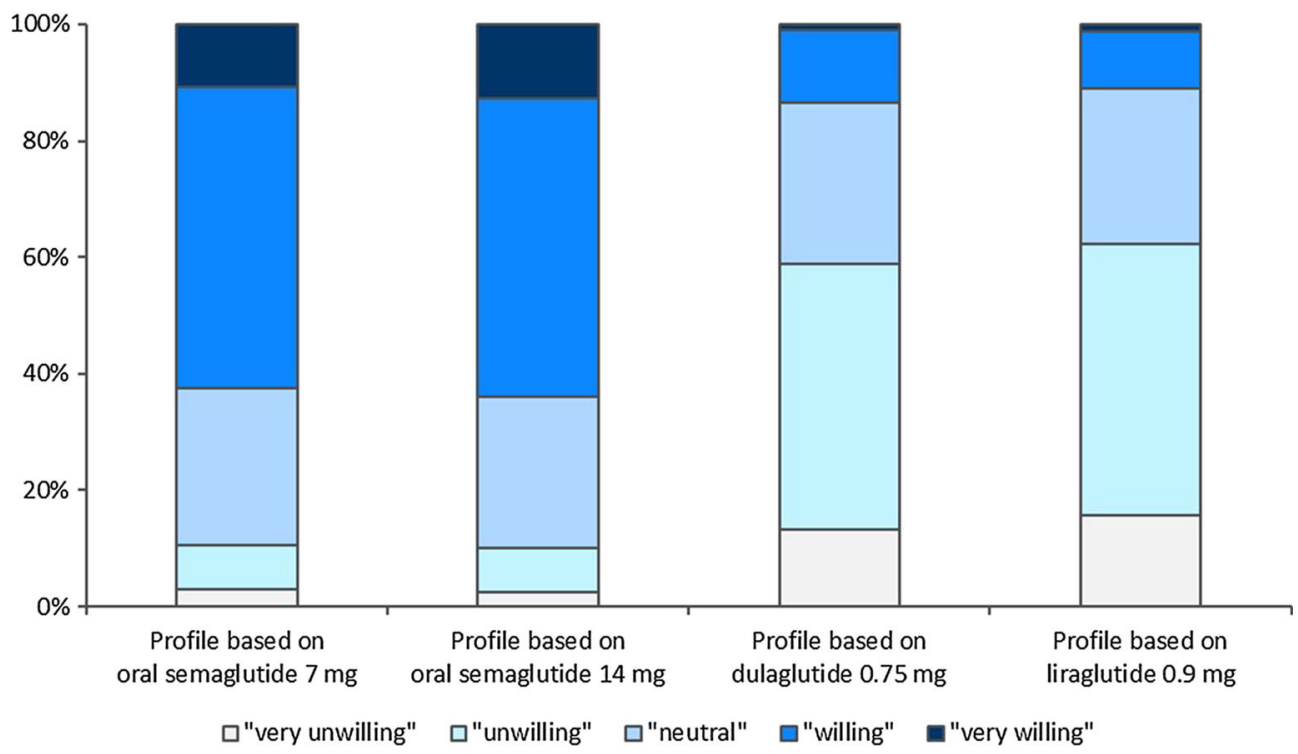

Fig. 4 Respondents' willingness to initiate treatment with four profiles based on actual therapies

\section{DISCUSSION}

In this survey, Japanese patients with T2D preferred therapy profiles reflecting orally administered semaglutide $7 \mathrm{mg}$ or $14 \mathrm{mg}$, over those of dulaglutide $0.75 \mathrm{mg}$ or liraglutide $0.9 \mathrm{mg}$ (the two most widely used injectable GLP-1 RAs in Japan). Analyses of hypothetical choice sets showed that mode and frequency of administration was the most important attribute in this decision, alongside risk of nausea. In addition, these patients were also substantially more willing to initiate treatment with therapy profiles based on orally administered semaglutide, of either dose, compared to dulaglutide and liraglutide.

Evaluable survey responses were provided by a sample of 500 injectable-naïve Japanese 
patients with $\mathrm{T} 2 \mathrm{D}$, with uncontrolled $\mathrm{HbA}_{1 \mathrm{c}}$ $(\geq 7 \%)[8,9]$. The diabetes-related characteristics of this sample may allow the survey results to be generalised to other Japanese patients with T2D who are offered treatment with GLP-1 RA therapies. Approximately three-quarters of respondents had $\mathrm{HbA}_{1 \mathrm{c}}$ in the range of $\geq 7 \%$ to $<8 \%$, and no respondent had ever received injectable GLP-1 therapy, or injectable insulin. As insulin is indicated only when glycaemic goals cannot be reached with oral antidiabetic therapy or GLP-1 RA therapy [8], the respondents to the current survey may therefore be considered candidates for intensified treatment with GLP-1 RA therapies, rather than insulin.

Change in $\mathrm{HbA}_{1 \mathrm{c}}$ was considered the least important attribute of treatment by respondents. This may be explained by comparing the magnitude of change described in the levels of this attribute with the $\mathrm{HbA}_{1 \mathrm{c}}$ levels of respondents. For the three-quarters of respondents who had $\mathrm{HbA}_{1 \mathrm{c}}<8 \%$, any of the presented reductions in $\mathrm{HbA}_{1 \mathrm{c}}$ would be sufficient to reach $<7 \%$ : the level recommended to prevent comorbidities $[8,9]$. In fact, for the majority of respondents (the $57.4 \%$ who had $\mathrm{HbA}_{1 \mathrm{c}}<$ $7.5 \%$ ), three of the four presented $\mathrm{HbA}_{1 \mathrm{c}}$ change levels would be sufficient to reach $\mathrm{HbA}_{1 \mathrm{c}}<6 \%$ : the level considered to be near normal glycaemia $[8,9]$. Therefore, it appears that relative effectiveness in reducing $\mathrm{HbA}_{1 \mathrm{c}}$ may not be a major differentiating factor between the tested GLP-1 RA therapies, in this population.

In addition, although higher weight loss was assumed to be always preferred by patients with $\mathrm{T} 2 \mathrm{D}$, this was not clearly reflected in the survey results. Although obese respondents $\left(\mathrm{BMI} \geq 25 \mathrm{~kg} / \mathrm{m}^{2}\right.$ ) placed a substantially higher relative importance on weight loss relative to non-obese respondents (19.92\% versus $5.13 \%)$, the ranking of this attribute did not increase beyond third most important in this subgroup.

When comparing the results of this study to those of previous GLP-1 RA-focused DCEs conducted in Japan, it is clear that the choice of therapies used to generate attribute levels has a significant impact on the relative importance of attributes. In the current study, and in a previous DCE conducted by Gelhorn et al. (both of which compared daily and weekly GLP-1 RA therapies), administration-related attributes were considered most important [23]. However, in a previous DCE by Brooks et al. which compared therapies with similar administration characteristics (two weekly injectable GLP-1 RA therapies), the administration-related attribute was considered least important [22].

Although the previous DCE by Gelhorn et al. included an additional attribute type (hypoglycaemia), the relative importance of shared attributes appears similar to the current study: administration-related attributes being most important, followed by nausea, weight change, and then $\mathrm{HbA}_{1 \mathrm{c}}$ change [23].

This DCE survey was designed using insights from published literature, qualitative research (including interviews with patients and physicians), and recent clinical trial data. The final structure and content of the survey adhered to recommendations of good practice made by the International Society for Pharmacoeconomics and Outcomes Research [35], and also included multiple established tests of validity and consistency [36].

As in the two previous GLP-1 RA-focused DCE studies conducted in Japan [22, 23], attribute levels presented in the current study were based on Japanese clinical trial data for the therapies of interest. In the current study, all direct comparisons of profiles were based on data from the relevant Japanese head-to-head clinical trials, while also being unbranded when presented to respondents.

The sample size of the current study $(n=500)$ was also larger than those of two GLP1 RA-focused DCE studies conducted in Japan ( $n=161$ and $n=182)$ [22, 23], although smaller than some other studies conducted in the USA or internationally $(n=510-1482)[25,27,28]$.

The four attributes presented within this study were selected through substantial qualitative research, and included the two most common process attributes and two most common outcome attributes among similar patient preference studies: dosing frequency and type of delivery device (in this case combined), and $\mathrm{HbA}_{1 \mathrm{c}}$ change and nausea [37]. Although most other GLP-1 RA-focused DCE studies tested more attributes simultaneously (five $[22,25]$, six 
$[23,24]$, or eight attributes $[27,28])$, presenting only the four most relevant and differentiating attributes of treatment here may have aided respondents' understanding.

The qualitative research undertaken prior to the survey also included in-depth questioning to both patients and physicians on the most relevant and understandable methods of presenting attribute levels.

Respondents completed the DCE survey remotely, with no input from study researchers. However, although two previous GLP-1 RA-focused DCE studies used a trained moderator to administer preference tasks in person, online self-completion appears to be common in other such studies [22, 25-28].

The current study included a very high proportion of male respondents. However, the presence of a majority-male sample appears to be common in previous GLP-1 RA-focused DCE studies [22-25, 27, 28], clinical trials of GLP-1 RA therapies in Japan [16, 17, 38-42], and observational studies on T2D in Japan $[7,43,44]$. This may be explained by a higher prevalence of $\mathrm{T} 2 \mathrm{D}$ amongst men, by men being more likely to have uncontrolled disease (and therefore being eligible to participate in such studies), or by men being more willing to participate in clinical trials or preference research in this therapy area. Regardless, subgroup analyses by gender within the current study showed only minor significant differences relative to the overall analysis sample.

\section{CONCLUSIONS}

When injectable-naïve Japanese patients with T2D compare profiles of GLP-1 RA therapies, mode and frequency of administration, alongside nausea risk, appears to be the most important factor in their decision-making. These patients appear substantially more likely to prefer (and much more willing to initiate treatment with) a treatment like orally administered semaglutide (whether $7 \mathrm{mg}$ or $14 \mathrm{mg}$ ), relative to dulaglutide $0.75 \mathrm{mg}$ or liraglutide $0.9 \mathrm{mg}$. These findings highlight the unmet need for an effective and orally administered GLP-1 RA for the treatment of T2D in Japan.

\section{ACKNOWLEDGEMENTS}

The authors thank the interview participants and survey respondents who contributed to this study.

Funding. Adelphi Values PROVE were commissioned by Novo Nordisk to conduct and report this research. Journal publication and open-access fees were funded by Novo Nordisk.

Editorial Assistance. Editorial assistance was provided by Emma McBeath and Chris Beadle of Spirit Medical Communications, who were funded by Novo Nordisk.

Authorship. All named authors meet the International Committee of Medical Journal Editors (ICMJE) criteria for authorship for this article, take responsibility for the integrity of the work as a whole, and have given their approval for this version to be published.

Disclosures. Ataru Igarashi reports grants and other from Gilead Sciences KK., grants from Intuitive Surgical GK., grants from Boston Scientific Japan Inc., grants and personal fees from Pfizer Japan Inc., grants from Beckton Dickinson and Company, grants from Milliman Inc., personal fees and other from Terumo corporation, personal fees from Chugai Pharmaceuticals Inc., personal fees from Astellas Pharma Inc., other from Fuji film Inc., other from CSL Behring Japan Inc., personal fees from Sanofi Japan Inc., personal fees and other from Takeda Pharmaceutical Inc., personal fees from Nippon Boeringer Ingelheim Inc., personal fees from Ono pharmaceutical Inc., personal fees from Taiho pharmaceutical Co. Ltd., personal fees from Eisai Inc., personal fees from Abbvie GK, personal fees from Sumitomo Dainippon Pharma Inc., personal fees from Ayumi Pharmaceutical Inc., personal fees from Medilead Inc., personal fees from Novo Nordisk Japan Inc., personal fees from Novartis Pharma Inc., personal fees from GSK Inc., outside the submitted work.

Brian Bekker Hansen is an employee and shareholder of Novo Nordisk A/S, Søborg, Denmark. Jakob Langer is an employee of Novo 
Nordisk Pharma Ltd., Tokyo, Japan.

Hannah Collings and Robin Wyn are employees of Adelphi Values PROVE. Francesca Tavella and Neil Davies were employees of Adelphi Values PROVE at the time of the conduct and reporting of this research; Francesca Tavella is an employee of AstraZeneca; Neil Davies is an employee of MTech Access. Adelphi Values PROVE were commissioned by Novo Nordisk to conduct and report this research.

Compliance with Ethics Guidelines. This non-interventional study was conducted in accordance with all applicable regulations in Japan and the United Kingdom.

Ethics approval for conducting research with patients with T2D was sought from Clinical Research Promotion Network Japan (http:// www.sct-net.org/), and was granted on 20 December 2018 (approval number 201812-02). All eligible respondents also confirmed their willingness to participate, and gave explicit informed consent to participate in the survey, and for their demographic data and preference data to be captured and stored for research purposes, and reported in an anonymized manner.

Data Availability. The datasets generated during and/or analyzed during the current study are not publicly available as participants of this study did not agree for their individual data to be shared publicly.

Open Access. This article is licensed under a Creative Commons Attribution-NonCommercial 4.0 International License, which permits any non-commercial use, sharing, adaptation, distribution and reproduction in any medium or format, as long as you give appropriate credit to the original author(s) and the source, provide a link to the Creative Commons licence, and indicate if changes were made. The images or other third party material in this article are included in the article's Creative Commons licence, unless indicated otherwise in a credit line to the material. If material is not included in the article's Creative Commons licence and your intended use is not permitted by statutory regulation or exceeds the permitted use, you will need to obtain permission directly from the copyright holder. To view a copy of this licence, visit http://creativecommons.org/licenses/by$\mathrm{nc} / 4.0 /$.

\section{REFERENCES}

1. American Diabetes Association. Classification and diagnosis of diabetes: standards of medical care in diabetes-2018. Diabetes Care. 2018;41(Supplement 1):S13-27.

2. International Diabetes Federation. IDF Diabetes Atlas-Eighth Edition. 2017. http://www. diabetesatlas.org/. Accessed 19 Nov 2020.

3. Charvat H, Goto A, Goto M, et al. Impact of population aging on trends in diabetes prevalence: a meta-regression analysis of 160,000 Japanese adults. J Diabetes Investig. 2015;6(5):533-42.

4. International Diabetes Federation. Japan-Country report 2017 and 2045; 2017. https://reports. instantatlas.com/report/view/

704ee0e6475b4af885051bcec15f0e2c/JPN. Accessed 28 Sept 2020.

5. Kohro T, Yamazaki $T$, Sato $H$, et al. Trends in antidiabetic prescription patterns in Japan from 2005 to 2011. Int Heart J. 2013;54(2):93-7.

6. Nishimura R, Kato H, Kisanuki K, et al. Treatment patterns, persistence and adherence rates in patients with type 2 diabetes mellitus in Japan: a claims-based cohort study. BMJ Open. 2019;9(3): e025806.

7. Maegawa $\mathrm{H}$, editor. Clinical inertia in patients with type 2 diabetes treated with oral antidiabetic drugs: a Japanese cohort study. 62nd Annual Meeting of the Japan Diabetes Society; 2019.

8. Haneda $M$, Noda $M$, Origasa $H$, et al. Japanese clinical practice guideline for diabetes 2016. J Diabetes Investig. 2018;9(3):657-97.

9. Araki E, Haneda M, Kasuga M, et al. New glycemic targets for patients with diabetes from the Japan Diabetes Society. J Diabetes Investig. 2017;8(1): 123-5.

10. Inoue $\mathrm{M}$, Shiramoto $\mathrm{M}$, Oura T, Nasu R, Nakano M, Takeuchi M. Effect of once-weekly dulaglutide on glucose levels in Japanese patients with type 2 diabetes: findings from a phase 4 , randomized controlled trial. Diabetes Ther. 2019;10(3):1019-27. 
11. Kaku K, Rasmussen MF, Nishida T, Seino Y. Fiftytwo-week, randomized, multicenter trial to compare the safety and efficacy of the novel glucagonlike peptide- 1 analog liraglutide vs glibenclamide in patients with type 2 diabetes. J Diabetes Investig. 2011;2(6):441-7.

12. Kaku K, Rasmussen MF, Clauson $\mathrm{P}$, Seino $\mathrm{Y}$. Improved glycaemic control with minimal hypoglycaemia and no weight change with the oncedaily human glucagon-like peptide-1 analogue liraglutide as add-on to sulphonylurea in Japanese patients with type 2 diabetes. Diabetes Obes Metab. 2010;12(4):341-7.

13. Onishi Y, Koshiyama H, Imaoka T, Haber H, ScismBacon J, Boardman MK. Safety of exenatide once weekly for 52 weeks in Japanese patients with type 2 diabetes mellitus. J Diabetes Investig. 2013;4(2):182-9.

14. Seino Y, Stjepanovic A, Takami A, Takagi H. Safety, tolerability and efficacy of lixisenatide in combination with oral antidiabetic treatment in Japanese patients with type 2 diabetes: an open-label, multicenter study. J Diabetes Investig. 2018;9(1): 127-36.

15. Seino Y, Terauchi Y, Wang X, Watanabe D, Niemoeller E. Safety, tolerability and efficacy of lixisenatide as monotherapy in Japanese patients with type 2 diabetes mellitus: an open-label, multicenter study. J Diabetes Investig. 2018;9(1):108-18.

16. Seino $\mathrm{Y}$, Terauchi $\mathrm{Y}$, Osonoi $\mathrm{T}$, et al. Safety and efficacy of semaglutide once weekly vs sitagliptin once daily, both as monotherapy in Japanese people with type 2 diabetes. Diabetes Obes Metab. 2018;20(2):378-88.

17. Kaku K, Yamada Y, Watada H, et al. Safety and efficacy of once-weekly semaglutide vs additional oral antidiabetic drugs in Japanese people with inadequately controlled type 2 diabetes: a randomized trial. Diabetes Obes Metab. 2018;20(5): 1202-12.

18. Yamada Y, Katagiri H, Hamamoto Y, et al. Doseresponse, efficacy, and safety of oral semaglutide monotherapy in Japanese patients with type 2 diabetes (PIONEER 9): a 52-week, phase 2/3a, randomised, controlled trial. Lancet Diabetes Endocrinol. 2020;8(5):P377-91.

19. Yabe D, Nakamura J, Kaneto H, et al. Safety and efficacy of oral semaglutide versus dulaglutide in Japanese patients with type 2 diabetes (PIONEER 10): an open-label, randomised, activecontrolled, phase 3 a trial. Lancet Diabetes Endocrinol. 2020;8(5):P392-406.
20. von Arx LB, Kjeer T. The patient perspective of diabetes care: a systematic review of stated preference research. Patient. 2014;7(3):283-300.

21. Soekhai V, de Bekker-Grob EW, Ellis AR, Vass CM. Discrete choice experiments in health economics: past present and future. PharmacoEconomics. 2019;37(2):201-26.

22. Brooks A, Langer J, Tervonen T, Hemmingsen MP, Eguchi K, Bacci ED. Patient preferences for GLP-1 receptor agonist treatment of type 2 diabetes mellitus in Japan: a discrete choice experiment. Diabetes Ther. 2019;10(2):735-49.

23. Gelhorn HL, Bacci ED, Poon JL, Boye KS, Suzuki S, Babineaux SM. Evaluating preferences for profiles of glucagon-like peptide-1 receptor agonists among injection-naive type 2 diabetes patients in Japan. Patient Prefer Adherence. 2016;10:1337-48.

24. Gelhorn HL, Poon JL, Davies EW, Paczkowski R, Curtis SE, Boye KS. Evaluating preferences for profiles of GLP-1 receptor agonists among injectionnaive type 2 diabetes patients in the UK. Patient Prefer Adherence. 2015;9:1611-22.

25. Hauber AB, Nguyen H, Posner J, Kalsekar I, Ruggles J. A discrete-choice experiment to quantify patient preferences for frequency of glucagon-like peptide1 receptor agonist injections in the treatment of type 2 diabetes. Curr Med Res Opin. 2016;32(2): 251-62.

26. Polster M, Zanutto E, McDonald S, Conner C, Hammer M. A comparison of preferences for two GLP-1 products-liraglutide and exenatide-for the treatment of type 2 diabetes. J Med Econ. 2010;13(4):655-61.

27. Qin L, Chen S, Flood E, et al. Glucagon-like peptide1 receptor agonist treatment attributes important to injection-naive patients with type 2 diabetes mellitus: a multinational preference study. Diabetes Ther. 2017a;8(2):321-34.

28. Qin L, Chen S, Flood E, et al. Glucagon-like peptide1 receptor agonist treatment attributes important to injection-experienced patients with type 2 diabetes mellitus: a preference study in Germany and the United Kingdom. Diabetes Ther. 2017b;8(2): 335-53.

29. Aizaki H. Basic functions for supporting an implementation of choice experiments in R. J Stat Softw. 2012;50:1-24.

30. Lipkus IM, Samsa G, Rimer BK. General performance on a numeracy scale among highly educated samples. Med Decis Making. 2001;21(1):37-44. 
31. Chew LD, Bradley KA, Boyko EJ. Brief questions to identify patients with inadequate health literacy. Fam Med. 2004;36(8):588-94.

32. Ogawa W, Miyazaki S. Diagnosis criteria for obesity and obesity disease. Health Eval Promot. 2015;42(2):301-6.

33. Shiroiwa T, Fukuda T, Ikeda S, et al. Japanese population norms for preference-based measures: EQ5D-3L, EQ-5D-5L, and SF-6D. Qual Life Res. 2016;25(3):707-19.

34. Hauber AB, Gonzalez JM, Groothuis-Oudshoorn $\mathrm{CG}$, et al. Statistical methods for the analysis of discrete choice experiments: a report of the ISPOR conjoint analysis good research practices task force. Value Health. 2016;19(4):300-15.

35. Bridges JF, Hauber AB, Marshall D, et al. Conjoint analysis applications in health-a checklist: a report of the ISPOR Good Research Practices for Conjoint Analysis Task Force. Value Health. 2011;14(4): 403-13.

36. Janssen EM, Marshall DA, Hauber AB, Bridges JFP. Improving the quality of discrete-choice experiments in health: how can we assess validity and reliability? Expert Rev Pharmacoecon Outcomes Res. 2017;17(6):531-42.

37. Thieu VT, Robinson S, Kennedy-Martin T, Boye KS, Garcia-Perez LE. Patient preferences for glucagonlike peptide 1 receptor-agonist treatment attributes. Patient Prefer Adherence. 2019;13:561-76.

38. Emoto M, Terauchi Y, Ozeki A, Oura T, Takeuchi M, Imaoka T. A 1-year safety study of dulaglutide in Japanese patients with type 2 diabetes on a single oral hypoglycemic agent: an open-label, nonrandomized, phase 3 trial. Endocr J. 2015;62(12): 1101-14.

39. Odawara M, Miyagawa J, Iwamoto N, Takita $\mathrm{Y}$, Imaoka T, Takamura T. Once-weekly glucagon-like peptide-1 receptor agonist dulaglutide significantly decreases glycated haemoglobin compared with once-daily liraglutide in Japanese patients with type 2 diabetes: 52 weeks of treatment in a randomized phase III study. Diabetes Obes Metab. 2016;18(3):249-57.

40. Araki E, Inagaki N, Tanizawa Y, Oura T, Takeuchi M, Imaoka T. Efficacy and safety of once-weekly dulaglutide in combination with sulphonylurea and/or biguanide compared with once-daily insulin glargine in Japanese patients with type 2 diabetes: a randomized, open-label, phase III, non-inferiority study. Diabetes Obes Metab. 2015;17(10):994-1002.

41. Seino Y, Kaneko S, Fukuda S, et al. Combination therapy with liraglutide and insulin in Japanese patients with type 2 diabetes: a 36-week, randomized, double-blind, parallel-group trial. J Diabetes Investig. 2016;7(4):565-73.

42. Inagaki N, Atsumi $\mathrm{Y}$, Oura $\mathrm{T}$, Saito H, Imaoka T. Efficacy and safety profile of exenatide once weekly compared with insulin once daily in Japanese patients with type 2 diabetes treated with oral antidiabetes drug(s): results from a 26-week, randomized, open-label, parallel-group, multicenter, noninferiority study. Clin Ther. 2012;34(9):1892908.e1.

43. Yokoyama H, Oishi M, Takamura H, et al. Largescale survey of rates of achieving targets for blood glucose, blood pressure, and lipids and prevalence of complications in type 2 diabetes (JDDM 40). BMJ Open Diabetes Res. 2016;4(1):e000294.

44. Fujihara K, Igarashi R, Matsunaga S, et al. Comparison of baseline characteristics and clinical course in Japanese patients with type 2 diabetes among whom different types of oral hypoglycemic agents were chosen by diabetes specialists as initial monotherapy (JDDM 42). Medicine. 2017;96(7): e6122. 